\title{
Biogenic Palladium Enhances Diatrizoate Removal from Hospital Wastewater in a Microbial Electrolysis Cell
}

\author{
Bart De Gusseme, ${ }^{\dagger}$ Tom Hennebel, ${ }^{\dagger}$ Lynn Vanhaecke, ${ }^{\ddagger}$ Maarten Soetaert, ${ }^{\dagger}$ Joachim Desloover, ${ }^{\dagger}$ \\ Klaas Wille, ${ }^{\ddagger}$ Kim Verbeken, ${ }^{\S}$ Willy Verstraete, ${ }^{\dagger}$ and Nico Boon ${ }^{+, *}$
${ }^{\dagger}$ Laboratory of Microbial Ecology and Technology (LabMET), Faculty of Bioscience Engineering, Ghent University, Coupure Links 653, B-9000 Gent, Belgium.
${ }^{\ddagger}$ Laboratory of Chemical Analysis, Faculty of Veterinary Medicine, Ghent University, Salisburylaan 133, B-9820 Merelbeke, Belgium
${ }^{\S}$ Department of Materials Science and Engineering, Faculty of Engineering, Ghent University, Technologiepark 903,
B-9052 Gent, Belgium.

Supporting Information

ABSTRACT: To decrease the load of pharmaceuticals to the environment, decentralized wastewater treatment has been proposed for important pointsources such as hospitals. In this study, a microbial electrolysis cell (MEC) was used for the dehalogenation of the iodinated X-ray contrast medium diatrizoate. The presence of biogenic palladium nanoparticles (bio-Pd) in the cathode significantly enhanced diatrizoate removal by direct electrochemical reduction and by reductive catalysis using the $\mathrm{H}_{2}$ gas produced at the cathode of the MEC. Complete deiodination of $3.3 \mu \mathrm{M}\left(2 \mathrm{mg} \mathrm{L}^{-1}\right)$ diatrizoate from a synthetic medium was achieved after $24 \mathrm{~h}$ of recirculation at an applied voltage of $-0.4 \mathrm{~V}$. An equimolar amount of the deiodinated metabolite 3,5-diacetamidobenzoate $(\mathrm{DAB})$ was detected. Higher cell voltages increased the dehalogenation rates, resulting in a complete removal after $2 \mathrm{~h}$ at $-0.8 \mathrm{~V}$. At this cell voltage, the MEC was also able to remove $85 \%$ of diatrizoate from hospital effluent containing $0.5 \mu \mathrm{M}$

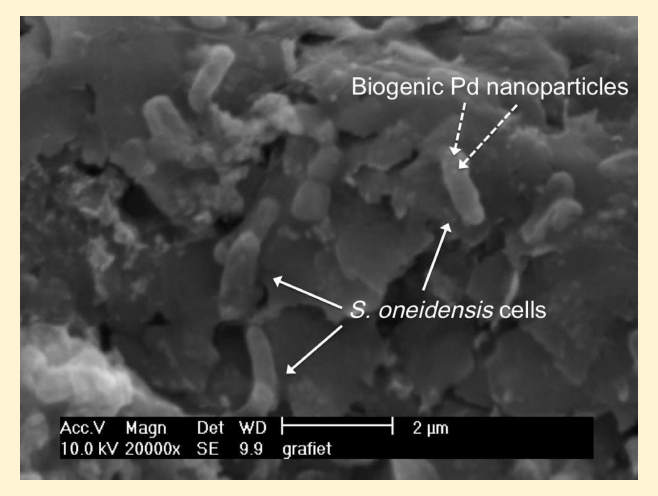
$\left(292 \mu \mathrm{g} \mathrm{L}^{-1}\right)$, after $24 \mathrm{~h}$ of recirculation. Complete removal was obtained when the effluent was continuously fed at a volumetric loading rate of $204 \mathrm{mg}$ diatrizoate $\mathrm{m}^{-3}$ total cathodic compartment (TCC) day ${ }^{-1}$ to the MEC with a hydraulic retention time of $8 \mathrm{~h}$. At $-0.8 \mathrm{~V}$, the MEC system could also eliminate $54 \%$ of diatrizoate from spiked urine during a 24 h recirculation experiment. The final product $\mathrm{DAB}$ was demonstrated to be removable by nitrifying biomass, which suggests that the combination of a MEC and bioPd in its cathode offers potential to dehalogenate pharmaceuticals, and to significantly lower the environmental burden of hospital waste streams.

\section{INTRODUCTION}

Diatrizoate belongs to the iodinated X-ray contrast media (ICM), a group of nonreactive diagnostics used for imaging of soft tissues, internal organs and blood vessels. ${ }^{1}$ Because this therapeutic class exhibits high biochemical stability and hydrophilic properties, ICM are excreted mostly unchanged within $24 \mathrm{~h} .{ }^{1,2}$ Consequently, significant loadings of these compounds are present in hospital wastewater, especially since ICM are administered in high doses (up to $200 \mathrm{~g}$ per patient). Because of their high polarity and persistence to biodegradation, their removal in wastewater treatment plants (WWTPs) is incomplete. WWTPs thus act as a gateway for ICM to enter water bodies, and diatrizoate has been regularly detected in municipal WWTP effluents $\left(4.1 \mu \mathrm{g} \mathrm{L}^{-1}\right.$ by Ternes and Hirsch $\left.{ }^{3}\right)$, surface water $\left(0.5 \mu \mathrm{g} \mathrm{L}^{-1}\right.$ by Seitz et al., ${ }^{4}$ but up to $100 \mu \mathrm{g} \mathrm{L}^{-1}$ by Ternes and $\left.\mathrm{Hirsch}^{3}\right)$ and even raw drinking water supplies $\left(1.2 \mu \mathrm{g} \mathrm{L}^{-1}\right.$ by Putschew et al. $\left.{ }^{5}\right)$. Up until now, not much is known about its fate and long-term effects and no toxic effect or bioaccumulation has been detected. ${ }^{6}$ Yet, according to the precautionary principle, the environmental input of such persistent and mobile compounds should be limited, especially because the presence of ICM can lead to the formation of iodoacetic acid, which can exert cytotoxic and genotoxic effects. ${ }^{7}$ Yet, the high degree of substitution of the benzene ring makes the compound even resistant to ozonation and other advanced oxidation techniques. ${ }^{8,9}$

New technologies using reductive catalysis were explored for ICM removal. Knitt et al. reported for the first time the rapid and complete hydrodehalogenation of diatriozate by means of hydrogen gas in combination with a supported Pd catalyst. ${ }^{10}$ Also biogenic Pd nanoparticles (bio-Pd) proved to be potent catalysts for diatrizoate reduction: ${ }^{11}$ the stepwise deiodination of diatrizoate was recently demonstrated in a suspension with bio-Pd produced by Shewanella oneidenis. When an electron donor is

Received: March 1, 2011

Accepted: $\quad$ May 31, 2011

Revised: $\quad$ May 30, 2011

Published: June 10, 2011 
provided, these bacteria serve as a reductant and a scaffold, reduce $\mathrm{Pd}(\mathrm{II})$ and deposit $\mathrm{Pd}(0)$ nanoparticles on their cell wall and in their periplasmatic space. ${ }^{12,13}$ If an external hydrogen donor is added to the biocatalyst as reactant, $90 \%$ removal of diatrizoate from WWTP effluent $(0.01 \mu \mathrm{M})$ could be achieved in a continuously fed membrane bioreactor. ${ }^{14}$ Yet, a major challenge remaining is the efficient supply of that hydrogen donor to the catalyst. $\mathrm{H}_{2}$ was demonstrated to be the most effective reactant but external supply of the gas often implies large operational costs and technical difficulties due to high safety risks. ${ }^{15}$

A promising configuration for $\mathrm{H}_{2}$ production is the microbial electrolysis cell (MEC). In a MEC, exoelectrogenic microorganisms oxidize organic substrates and pass electrons to the anode. ${ }^{16,17}$ These electrons travel through an external circuit to the cathode, where they can be consumed for $\mathrm{H}_{2}$ formation. ${ }^{18}$ To encourage the electrons to migrate to the cathodic compartment, a supplemental voltage is supplied to the electrical circuit. At $\mathrm{pH}$ 7 , the equilibrium potentials for the oxidation of, for example, acetate $(1 \mathrm{M})$ at the anode and reduction of protons at the cathode are -0.28 and- $0.42 \mathrm{~V}$ (vs standard hydrogen electrode, $\mathrm{SHE})$, respectively. As a consequence, the minimum theoretical voltage that has to be applied for $\mathrm{H}_{2}$ generation is $0.14 \mathrm{~V},{ }^{18}$ which is substantially lower than the voltage required for $\mathrm{H}_{2}$ production by conventional water electrolysis $(1.6-2.0 \mathrm{~V}) .^{19}$

To decrease the environmental burden of pharmaceutical point-sources such as hospitals, separate and decentralized treatment is being considered. ${ }^{20}$ Yet, new tools are warranted in order to deal with obsorbable organic halogens (AOX). In this study, a combination of bio-Pd with $\mathrm{H}_{2}$-production in a $\mathrm{MEC}$ system was examined for the catalytic reduction of diatrizoate. Batch recirculation experiments were conducted at different cell voltages, aiming for a fast and complete dehalogenation of the model compound. Subsequently, the feasibility of such a MEC for continuous removal of diatrizoate from hospital WWTP effluent was investigated. An assessment of the use of the MEC for separate diatrizoate removal from spiked urine was performed as well.

\section{MATERIALS AND METHODS}

Synthetic Medium Preparation and Production of Bio-Pd Coated Graphite. A synthetic electrolyte medium was prepared for the MEC experiments containing $6 \mathrm{~g} \mathrm{Na}_{2} \mathrm{HPO}_{4} \cdot 2 \mathrm{H}_{2} \mathrm{O} \mathrm{L}{ }^{-1}$, $3 \mathrm{~g} \mathrm{KH}_{2} \mathrm{PO}_{4} \mathrm{~L}^{-1}, 0.1 \mathrm{~g}\left(\mathrm{NH}_{4}\right)_{2} \mathrm{HPO}_{4} \mathrm{~L}^{-1}, 0.1 \mathrm{~g} \mathrm{Ca}_{3}\left(\mathrm{PO}_{4}\right)_{2} \mathrm{~L}^{-1}$ and $0.5 \mathrm{~mL} \mathrm{~L}^{-1}$ of a trace metal solution previously described by Rabaey et al. ${ }^{21}$ The $\mathrm{pH}$ of the medium was $7.1 \pm 0.1$. For the diatrizoate tests, $3.3 \mu \mathrm{M}\left(2 \mathrm{mg} \mathrm{L}^{-1}\right)$ was supplemented to the synthetic medium using a $8.1 \mathrm{M}$ stock solution (AppliChem, Germany) in water. Bio-Pd was produced by S. oneidensis MR-1 in $\mathrm{M} 9$ medium ( $\mathrm{Pd} /$ cell dry weight ratio of $1 / 1)$, as previously described. ${ }^{12}$ A $500 \mathrm{mg}$ bio-Pd L ${ }^{-1}$ suspension was mixed with graphite and dried for five days at $105^{\circ} \mathrm{C}$ to obtain finally $5 \mathrm{mg}$ $\mathrm{Pd} \mathrm{g}^{-1}$ graphite.

Microbial Electrolysis Cell. The MEC was constructed with two Plexiglas frames $(12.5 \times 8 \times 1.5 \mathrm{~cm}$ per frame $)$, which resulted in a total anodic and cathodic compartment (TCC) of $0.150 \mathrm{~L}$ (see Supporting Information (SI) Figure SI1). Both compartments were packed with $160 \mathrm{~g}$ of graphite granules (type 00514, $\varphi: 1.5-5 \mathrm{~mm}$, Mersen, France), and in each of them, a graphite rod current collector ( $\varphi: 5 \mathrm{~mm}$, Morgan, Belgium) was provided to connect them with the external electrical circuitry. Between the anodic and cathodic frames, a cation exchange membrane was installed (Ultrex CMI7000, Membranes International Inc., New Jersey). A power source (PL-3003D, Protek, New Jersey) was used to supply an external voltage between anode and cathode, and the voltage difference was measured between both compartments. The voltage drop over a $1 \Omega$ resistor in circuitry was monitored to determine the current production. The cathode potential was measured by monitoring the voltage difference between the cathode and an $\mathrm{Ag} / \mathrm{AgCl}$ reference electrode (assumed $+0.197 \mathrm{~V}$ vs SHE). All measurements were registered by a 34970A Data Acquisition Switch unit (Agilent, Belgium).

Start-Up of the MEC and Batch Recirculation Experiments. The synthetic medium was sparged with $\mathrm{N}_{2}$, brought into $2 \mathrm{~L}$ vessels, and separately recirculated through the anodic and cathodic compartment at $17 \mathrm{~mL} \min ^{-1}$ (see SI Figure SI1). Sodium acetate $\left(2 \mathrm{~g} \mathrm{~L}^{-1}\right)$ was added to the anode medium as feed. The anode compartment was inoculated with $25 \mathrm{~mL}$ of anode medium from a previous MEC, running for 30 months and fed with $1 \mathrm{~g} \mathrm{~L}^{-1}$ acetate by recirculation. ${ }^{22}$ After the successful start-up of the MEC, the anodic and cathodic medium were replaced, $2 \mathrm{~g} \mathrm{~L}^{-1}$ sodium acetate was provided to the anodic medium, and the cathodic medium was spiked with $3.3 \mu \mathrm{M}$ $\left(2 \mathrm{mg} \mathrm{L}^{-1}\right)$ diatrizoate. A batch recirculation experiments with noncoated graphite granules was performed during $24 \mathrm{~h}$ at an applied voltage of $-0.8 \mathrm{~V}$. Subsequently, the graphite granules in the cathode were replaced by the bio-Pd coated graphite granules (SI Figure SI2). Batch MEC runs were performed in open circuit, and in closed circuit at various applied voltages: $-0.4,-0.6$, and $-0.8 \mathrm{~V}$. Before every test run, the MEC was conditioned overnight to the applied voltage. After each experiment, the anode and cathode medium were replenished. Samples for analysis of $\mathrm{H}_{2}, \mathrm{Pd}, \mathrm{I}$, diatrizoate and its metabolites were taken at regular intervals.

Continuous Experiments. Synthetic medium with $3.3 \mu \mathrm{M}$ ( $2 \mathrm{mg} \mathrm{L}^{-1}$ ) diatrizoate was continuously pumped through the net cathodic compartment (NCC) with a volume of $0.070 \mathrm{~L}$. During operation, the active volume was measured to be $0.035 \mathrm{~L}$ due to gas accumulation. Continuous experiments were performed during $48 \mathrm{~h}$, at a hydraulic retention time (HRT) of $0.5,2$, 4 , and $8 \mathrm{~h}$ in the cathodic compartment. In the anodic compartment, synthetic medium with $2 \mathrm{~g} \mathrm{~L}^{-1}$ sodium acetate was recirculated. The voltage applied to the MEC was $-0.8 \mathrm{~V}$. Samples were regularly taken for analysis of diatrizoate and its metabolites.

Tests with Hospital WWTP Effluent. The hospital WWTP is a conventional activated sludge system, treating an average flow rate of $250 \mathrm{~m}^{3} \mathrm{~d}^{-1}$. Samples of the influent and effluent of the WWTP were collected at two different dates (Table 1). The effluent sample with the highest diatrizoate load (December eighth) was taken as a "worst case" model with environmentally relevant concentration. The $\mathrm{pH}$ of the effluent was $7.2 \pm 0.2$. More characteristics of this sample are given in the SI (S3, and Table SI1). A similar batch experiment as described above was performed to examine diatrizoate removal in this matrix. Bio-Pd coated graphite was present in the cathode and the applied voltage was $-0.8 \mathrm{~V}$. Similar continuous experiments were also performed at a HRT of 4 and $8 \mathrm{~h}$. Synthetic medium with $2 \mathrm{~g} \mathrm{~L}^{-1}$ sodium acetate was recirculated at the anodic compartment. Samples were taken at regular intervals for analysis of diatrizoate and 3,5-diacetamidobenzoate (DAB).

Spiked Urine Experiment. To examine degradation of diatrizoate in urine, a pure urine sample was spiked with $3.3 \mu \mathrm{M}$ 
Table 1. Concentrations of Diatrizoate Encountered in the Influent and Effluent Samples of the Hospital WWTP and the Diatrizoate Removal Efficiency ${ }^{a}$

$\begin{array}{lccc}\begin{array}{ccc}\text { sampling } \\ \text { date }\end{array} & \begin{array}{c}\text { diatrizoate in } \\ \text { influent }\left(\mu \mathrm{g} \mathrm{L}^{-1}\right)\end{array} & \begin{array}{c}\text { diatrizoate in } \\ \text { effluent }\left(\mu \mathrm{g} \mathrm{L}^{-1}\right)\end{array} & \begin{array}{c}\text { diatrizoate } \\ \text { removal (\%) }\end{array} \\ \begin{array}{l}\text { November 18 } \\ \text { December 8 }\end{array} & 803 \pm 5 & 99 \pm 3 & 75 \pm 2 \\ \text { Deces } & 292 \pm 17 & 64 \pm 4 \\ \begin{array}{l}\text { a Samples were } \\ \text { (November 18th) and dry (December 8th) weather conditions. }\end{array}\end{array}$

(2 $\mathrm{mg} \mathrm{L}^{-1}$ ) diatrizoate. The urine contained $6.2 \pm 0.6 \mathrm{mg}$ $\mathrm{NO}_{3}{ }^{-}-\mathrm{N} \mathrm{L}^{-1}, 505.1 \pm 3.8 \mathrm{mg} \mathrm{SO}_{4}{ }^{2-}-\mathrm{S} \mathrm{L}^{-1}$ and $552.8 \pm 5.1 \mathrm{mg}$ $\mathrm{PO}_{4}{ }^{3-}-\mathrm{P} \mathrm{L}^{-1}$, and its $\mathrm{pH}$ was $6.9 \pm 0.1$. Two liters were provided by recirculation $\left(6.67 \mathrm{~L} \mathrm{~L}^{-1} \mathrm{TCC} \mathrm{h}{ }^{-1}\right)$ to the cathodic compartment with bio-Pd coated graphite granules. A $24 \mathrm{~h}$ batch recirculation experiment was performed at an applied voltage of $-0.8 \mathrm{~V}$. Samples were taken at regular intervals for analysis of diatrizoate.

Chromatographic Analysis of Diatrizoate and Its Metabolites. For chromatographic analysis of diatrizoate and the complete deiodinated compound DAB in synthetic medium, $2 \mathrm{~mL}$ samples were filtered over a $0.22 \mu \mathrm{m}$ filter (Millipore, Massachusetts) in a glass HPLC vial and stored at $4{ }^{\circ} \mathrm{C}$ in the dark prior to analysis. Both compounds were analyzed by reverse phase HPLC as described in the SI (S4.1). For the detection of diatrizoate and $\mathrm{DAB}$ at lower concentrations, ultrahigh performance liquid chromatography coupled to tandem mass spectrometry (U-HPLC-MS/MS) was used (S4.1). Influent and effluent samples of the hospital WWTP were filtered and stored as described above. For the detection of diatrizoate and DAB in this matrix, U-HLC-MS/MS was performed (S4.2). The metabolites Dia- $\mathrm{HI}_{2}$ and Dia- $\mathrm{H}_{2} \mathrm{I}$ were monitored and identified using multiple mass spectrometry (LC-MS ${ }^{n}$ ), according to Hennebel et al. ${ }^{11}$

Chemical aAnalyses. Similarly to the work performed by Zwiener et al., the total iodine content of the organic and inorganic compounds (including free iodide) was measured, as a tool to examine sorption of diatrizoate or its transformation products. $^{23}$ The total iodine content was determined by means of inductive coupled plasma optical emission spectrometry (ICPOES) (Varian Vista MPX, Varian, California). The palladium concentration was measured using a Shimadzu AA-6300 atomic absorption spectroscope (AAS) (Japan). The $\mathrm{H}_{2}$ concentration in the gas phase of the MEC was analyzed with a Compact GC with a thermal conductivity detector (Global Analyzer Solutions, The Netherlands), equipped with a PoraBOND Q precolumn and a Molsieve 5A column (Varian). Conductivity was measured using a Consort C833 multichannel analyzer with EC-electrode (Consort, Belgium).

\section{RESULTS}

Batch Recirculation Experiments with a MEC for the Treatment of Synthetic Medium with Diatrizoate. The results of the batch recirculation experiments with the MEC to treat synthetic medium with $3.3 \mu \mathrm{M}$ diatrizoate are given in Figure 1. First, graphite granules without bio-Pd were used in the cathode compartment, which resulted in an $84.1 \pm 3.5 \%$ removal after $24 \mathrm{~h}$ recirculation at an applied voltage of- $0.8 \mathrm{~V}$. Direct electrochemical reduction of diatrizoate was thus possible at a cathode potential of $-0.83 \mathrm{~V}$ vs SHE (Table 2), but the deiodination was

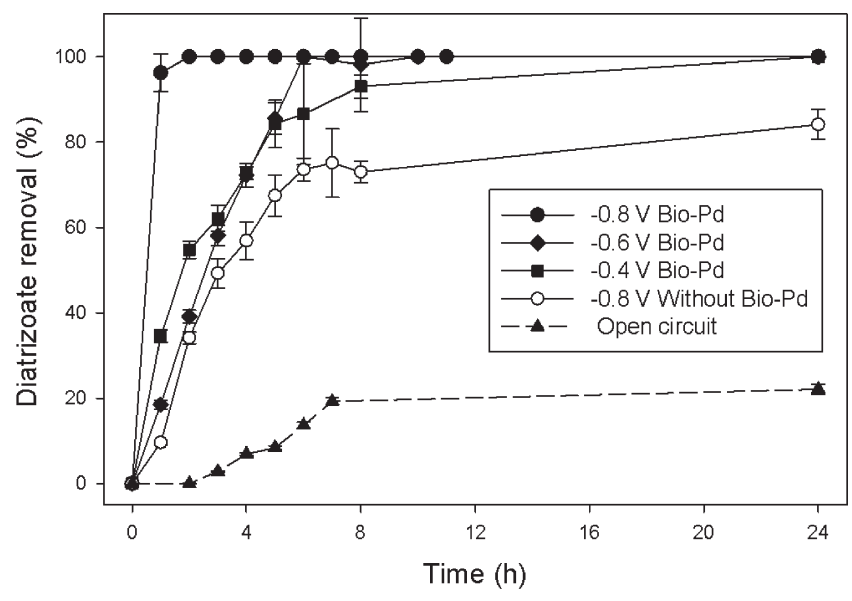

Figure 1. Batch recirculation experiments for the treatment of synthetic medium. Percentage of diatrizoate removal as a function of time using the MEC with bio-Pd coated graphite granules in the cathode. The MEC runs were performed at different applied voltages $(-0.4 \mathrm{~V},-0.6 \mathrm{~V}$, and $-0.8 \mathrm{~V})$ and in open circuit. A control experiment at an applied voltage of $-0.8 \mathrm{~V}$ using noncoated graphite granules in the cathode is included as well. Error bars represent the standard deviation of triplicate measurements (sometimes smaller than symbols).

not complete since not more than $0.3 \pm 0.1 \mu \mathrm{M}$ of the fully deiodinated metabolite $\mathrm{DAB}$ was detected in the medium after $24 \mathrm{~h}$.

Subsequently, bio-Pd was coated on graphite granules ( $5 \mathrm{mg}$ $\mathrm{Pd} \mathrm{g}^{-1}$ ) meant for the cathodic compartment of a MEC. SEM analyses showed that the dead S. oneidensis cells carrying biogenic Pd particles were still intact, and that they were well attached to the graphite surface (see Chapter S2 and Figure SI2 in the SI). Application of a voltage of $-0.4 \mathrm{~V}$ in closed circuit already resulted in a $100 \%$ removal of diatrizoate after $24 \mathrm{~h}$. At a cathode potential of $-0.43 \mathrm{~V}$ vs SHE (Table 2), hydrogen formation was clearly visible as gas bubbles on the graphite granules of the cathode, and the presence of $\mathrm{H}_{2}$ was confirmed by GC analysis (see SI Chapter S6 and Figure SI4). The deiodination of diatrizoate was complete, and $3.3 \pm 0.2 \mu \mathrm{M}$ of the transformation product $\mathrm{DAB}$ was found after $24 \mathrm{~h}$ (Figure $2 \mathrm{~A}$ ). This intermediate was shown to be biodegradable, as $4.2 \mu \mathrm{M}$ DAB was completely removed by nitrifying sludge after $24 \mathrm{~h}$ of incubation (see biodegradability assay in SI Chapter S9). In addition, the total iodine content of the organic and inorganic products in solution remained stable (around $1.3 \mathrm{mg} \mathrm{L}^{-1}$ ), indicating that no sorption of the compound and its iodinated metabolites took place.

Influence of the Applied Voltage and the Cathode Potential. The removal of diatrizoate was proportional to the applied voltage and the cathode potential (Table 2). When applying a voltage of $-0.6 \mathrm{~V}$ and $-0.8 \mathrm{~V}$, the cathode potential was lowered to $-0.51 \mathrm{~V}$ and $-0.92 \mathrm{~V}$ vs SHE, respectively (Table 2), resulting in an increased diatrizoate removal rate (100\% removal after 10 and $2 \mathrm{~h}$, respectively). This was related to a larger production of gas in the cathode (confirmed by GC analysis), which is in accordance with the increasing current production that was measured at lower cathode potentials (Table 2). In the batch experiment at $-0.8 \mathrm{~V}$ with bio-Pd coated graphite granules, $3.3 \pm 0.1 \mu \mathrm{M}$ of $\mathrm{DAB}$ was measured in the medium after $2 \mathrm{~h}$, demonstrating that lowering the cathode potential to $-0.92 \mathrm{~V}$ vs SHE (Table 2) resulted in a fast and complete deiodination of diatrizoate. In open circuit, the diatrizoate removal was 
Table 2. Overview of the Cell Voltage, The Cathodic Potential and the Current Production during the Different MEC Experiments

\begin{tabular}{|c|c|c|c|}
\hline MEC experiment & cell voltage $(\mathrm{mV})$ & cathodic potential (mV vs SHE) & current production $\left(\mathrm{A} \mathrm{m}^{-3} \mathrm{NCC}\right)^{a}$ \\
\hline batch run synthetic medium at $-0.4 \mathrm{~V}$ & $-452 \pm 20$ & $-432 \pm 38$ & $266 \pm 184$ \\
\hline batch run synthetic medium at $-0.6 \mathrm{~V}$ & $-561 \pm 6$ & $-511 \pm 39$ & $352 \pm 65$ \\
\hline batch run synthetic medium at $-0.8 \mathrm{~V}$ & $-828 \pm 26$ & $-918 \pm 25$ & $552 \pm 13$ \\
\hline batch run synthetic medium at $-0.8 \mathrm{~V}$ without bio-Pd & $-815 \pm 7$ & $-826 \pm 33$ & $598 \pm 94$ \\
\hline batch run hospital WWTP effluent at $-0.8 \mathrm{~V}$ & $-821 \pm 4$ & $-732 \pm 43$ & $495 \pm 57$ \\
\hline batch run urine at $-0.8 \mathrm{~V}$ & $-806 \pm 8$ & $-693 \pm 46$ & $699 \pm 110$ \\
\hline continuous run synthetic medium at $-0.8 \mathrm{~V} \mathrm{HRT}=0.5 \mathrm{~h}$ & $-787 \pm 5$ & $-742 \pm 12$ & $442 \pm 24$ \\
\hline continuous run synthetic medium at $-0.8 \mathrm{~V} \mathrm{HRT}=2 \mathrm{~h}$ & $-816 \pm 1$ & $-907 \pm 7$ & $440 \pm 9$ \\
\hline continuous run synthetic medium at $-0.8 \mathrm{~V} \mathrm{HRT}=4 \mathrm{~h}$ & $-825 \pm 1$ & $-882 \pm 7$ & $451 \pm 11$ \\
\hline continuous run synthetic medium at $-0.8 \mathrm{~V} \mathrm{HRT}=8 \mathrm{~h}$ & $-808 \pm 3$ & $-908 \pm 9$ & $590 \pm 32$ \\
\hline continuous run hospital WWTP effluent at $-0.8 \mathrm{~V} \mathrm{HRT}=4 \mathrm{~h}$ & $-823 \pm 1$ & $-897 \pm 5$ & $480 \pm 17$ \\
\hline $\begin{array}{l}\text { continuous run hospital WWTP effluent at }-0.8 \mathrm{~V} \mathrm{HRT}=8 \mathrm{~h} \\
\text { NCC: net cathodic compartment. }\end{array}$ & $-808 \pm 4$ & $-923 \pm 2$ & $588 \pm 34$ \\
\hline
\end{tabular}

$22.1 \pm 1.1 \%$ after $24 \mathrm{~h}$, and no DAB concentrations above the LOD could be detected. It should be noted that the cathodic potential in open circuit increased with $0.32 \mathrm{~V}$ in the first hour of the experiment (from -0.07 to $0.25 \mathrm{~V}$ vs SHE). Subsequently, the potential decreased again until an equilibrium of $-0.08 \pm$ $0.03 \mathrm{~V}$ vs SHE was reached between 10 and $24 \mathrm{~h}$.

Batch Recirculation Experiment to Treat Hospital WWTP Effluent with a MEC. To examine the use of the MEC system for diatrizoate removal in an environmental matrix, the effluent of a WWTP that exclusively treats hospital wastewater was sampled (Table 1). As a "worst case scenario", the sample with the highest diatrizoate load was used in the batch recirculation experiment. Figure $2 \mathrm{~B}$ shows that the diatrizoate removal amounted to $84.9 \pm 7.6 \%$ after $24 \mathrm{~h}$, when a voltage of $-0.8 \mathrm{~V}$ was applied (resulting in a cathode potential of $-0.73 \mathrm{~V}$, Table 2 ). Formation of $0.09 \pm 0.01 \mu \mathrm{M}$ DAB was observed after $24 \mathrm{~h}$, which means that the mass balance with the complete deiodinated transformation product was only closed for $29 \%$. Yet, the total iodine concentration in solution remained constant, suggesting that there is no sorption of the compound and its iodinated metabolites.

Continuous Treatment of Synthetic Medium and Hospital WWTP Effluent. In order to test the ability of the MEC to continuously remove diatrizoate, synthetic medium was dosed to the cathodic compartment at different HRT (Figure 3A). Applying a cell voltage of $-0.8 \mathrm{~V}$, a HRT of $0.5 \mathrm{~h}$ was too short to ensure complete removal of diatrizoate. Although an initial removal of $95.1 \pm 9.2 \%$ was observed, the removal efficiency decreased to an average of $75.7 \pm 2.9 \%$ between 24 and $48 \mathrm{~h}$. In contrast, a complete removal was obtained when a HRT of 2, 4, or $8 \mathrm{~h}$ was applied. At a HRT of 2, 4, and $8 \mathrm{~h}, \mathrm{DAB}$ concentrations up to $1.2 \pm 0.1,0.7 \pm 0.1$, and $0.4 \pm 0.1 \mu \mathrm{M}$ were, respectively, detected. This means that the mass balance with $\mathrm{DAB}$ was only closed for 36,22 , and $13 \%$, respectively. To further examine the deiodination efficiency, a semiquantitative analysis of the metabolites with one (Dia- $\left.\mathrm{HI}_{2}\right)$ or two $\left(\right.$ Dia- $\left.\mathrm{H}_{2} \mathrm{I}\right) \mathrm{I}$ atoms cleaved was performed. These compounds could not be quantified due to a lack of available reference standards but $\mathrm{LC}-\mathrm{MS}^{\mathrm{n}}$ revealed that Dia- $\mathrm{HI}_{2}$ and Dia- $\mathrm{H}_{2} \mathrm{I}$ were still present at a HRT of 0.5 and $2 \mathrm{~h}$. Yet, these products were not observed at a HRT of 4 and $8 \mathrm{~h}$, corresponding with volumetric loading rates of $2.8 \mathrm{~g}$ diatrizoate

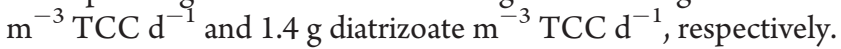

As a consequence, the continuous experiments with hospital WWTP effluent were conducted at a HRT of 4 and $8 \mathrm{~h}$ as well. Figure $3 \mathrm{~B}$ shows that the removal efficiency was immediately very high ( $95 \%$ and $96 \%$ after one HRT, respectively). In the case of a HRT of $4 \mathrm{~h}$, however, traces of diatrizoate were still detected. On the contrary, the removal was complete after $30 \mathrm{~h}$ of continuous operation at a HRT of $8 \mathrm{~h}$, indicating that continuous removal of diatrizoate from a hospital WWTP effluent is possible at a volumetric loading rate of $204 \mathrm{mg}^{\text {diatrizoate } \mathrm{m}^{-3} \mathrm{TCC} \mathrm{d}} \mathrm{d}^{-1}$.

Application of a MEC for Diatrizoate Removal from Spiked Urine. An interesting alternative to decrease the pharmaceutical load in hospital wastewater is separate collection and further treatment of the urine of patients, especially of those subjected to ICM. To examine the feasibility of the MEC with bio-Pd coated graphite to remove diatrizoate from urine, a batch experiment was performed with urine spiked with $3.3 \mu \mathrm{M}$ diatrizoate (Figure 4). During recirculation at an applied voltage of $-0.8 \mathrm{~V}$, a gradual removal of diatrizoate was observed until a maximum of $53.8 \pm$ $1.7 \%$ was reached (between 3 and $24 \mathrm{~h}$ ). $\mathrm{H}_{2}$ formation was detected in the cathodic compartment. Furthermore, the current produced in this experiment was the highest of all experiments at $-0.8 \mathrm{~V}$, which is probably related to the higher conductivity of urine compared to synthetic medium and hospital WWTP effluent $\left(28.43 \pm 0.08 \mathrm{mS} \mathrm{cm}^{-1}\right.$ vs $8.40 \pm 0.03 \mathrm{mS} \mathrm{cm}^{-1}$ and $2.30 \pm 0.02 \mathrm{mS} \mathrm{cm}^{-1}$, respectively).

\section{DISCUSSION}

Bio-Pd Enhances Diatrizoate Removal at the Cathode. The presence of bio-Pd in the cathode compartment clearly enhanced the dehalogenation of diatrizoate. At an applied voltage of $-0.8 \mathrm{~V}$, comparison of the results obtained by the MEC with and without bio-Pd, showed that the biocatalyst not only increased the removal rate of diatrizoate. Also the extent of deiodination was more complete when bio-Pd was present in the cathode compartment. The dehalogenation of diatrizoate may occur through two possible reduction mechanisms (see Chapter S5 and Figure SI3 in the SI), and bio-Pd can influence both of them: (i) direct electrochemical reduction at the cathode, and (ii) reductive bioPd catalysis using the hydrogen gas produced at the cathode.

The direct electrochemical reduction of the ICM iopromide at the cathode of a MEC was recently described by $\mathrm{Mu}$ et al. ${ }^{24}$ 


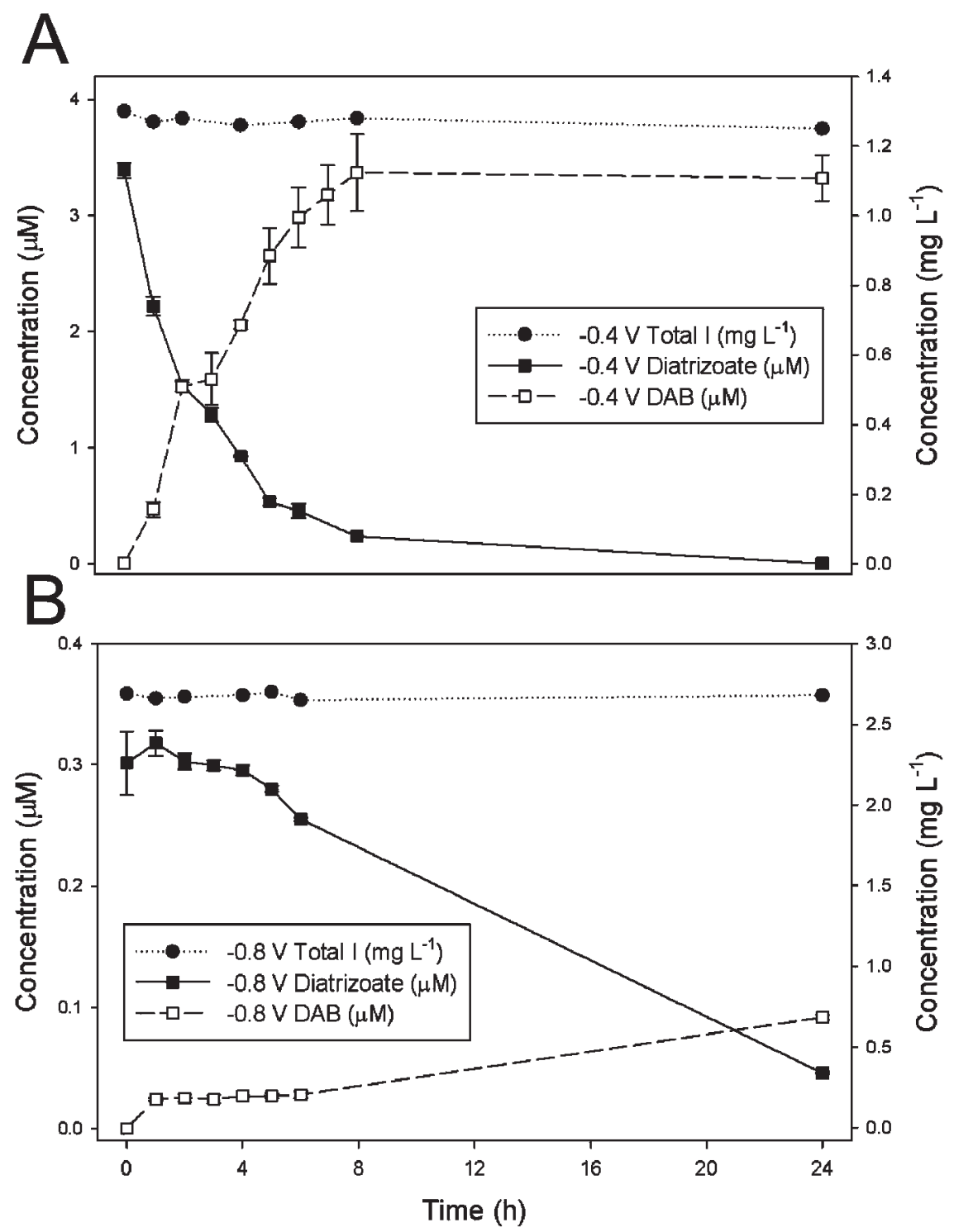

Figure 2. (A) Removal of diatrizoate and formation of $\mathrm{DAB}$ as a function of time in the batch experiment treating synthetic medium at an applied voltage of $-0.4 \mathrm{~V}$. "Total I" refers to the total iodine content of the organic and inorganic compounds and free iodine ions, expressed in mg $\mathrm{L}^{-1}$ (right axis). (B) Batch experiments for the treatment of hospital WWTP effluent, with the removal of diatrizoate and formation of DAB as a function of time in case of an applied voltage of $-0.8 \mathrm{~V}$. Error bars represent the standard deviation of triplicate measurements (sometimes smaller than symbols).

These authors showed dehalogenation of iopromide at a cathode potential of $-0.85 \mathrm{~V}$ vs SHE, while the removal at a cathode potential of $-0.5 \mathrm{~V}$ vs SHE was found to be negligible. Furthermore, it was demonstrated that iopromide could be completely dehalogenated at a cathode potential of $-0.8 \mathrm{~V}$ or lower, while only one or two iodines were released when the cathode potential was controlled at $-0.6 \mathrm{~V}$ or $-0.7 \mathrm{~V}$ vs SHE. In our study, complete dehalogenation of diatrizoate was already possible at a cathode potential of $-0.43 \mathrm{~V}$ vs SHE when bio-Pd was present, while the dehalogenation was incomplete at a cathode potential of $-0.81 \mathrm{~V}$ vs SHE without bio-Pd at the cathode. The lowering of the cathode overpotential by Pd might partially explain this, as recently reported for the Pd coating of carbon electrodes. ${ }^{25}$

On the other hand, hydrogen gas was produced at the cathode, which can serve as hydrogen donor for the catalytic hydrodehalogenation of diatrizoate, as demonstrated in the batch experiments with suspended bio-Pd (see SI Chapter S7). The presence of bio-Pd at the cathode thus enhances diatrizoate removal by reductive catalysis as well, and the $\mathrm{Pd}$ nanoparticles themselves are known to facilitate hydrogen production by a MEC. ${ }^{25}$ As a consequence, $\mathrm{H}_{2}$ production at an applied voltage of $-0.4 \mathrm{~V}$ and a cathode potential of $-0.43 \mathrm{~V}$ vs SHE was sufficient to remove diatrizoate completely in a $24 \mathrm{~h}$ batch experiment. Rozendal et al. already reported on $\mathrm{H}_{2}$ production at an applied voltage of $-0.5 \mathrm{~V}$, and expected to lower the required voltage to $-(0.3-0.4) \mathrm{V}$ by optimization of the MEC design. ${ }^{18}$ Because of various electrochemical losses, ${ }^{17,26}$ the required voltage that needed to be applied was higher than the theoretically $-0.14 \mathrm{~V}$. Nevertheless, the applied voltages for biocatalyzed electrolysis were much lower compared to direct electrolysis of water, which minimally requires $-1.6 \mathrm{~V}^{27}$

From the above, it is clear that both the direct electrochemical reduction and the bio-Pd catalysis are probably responsible for the dehalogenation of diatrizoate. It is however difficult to 

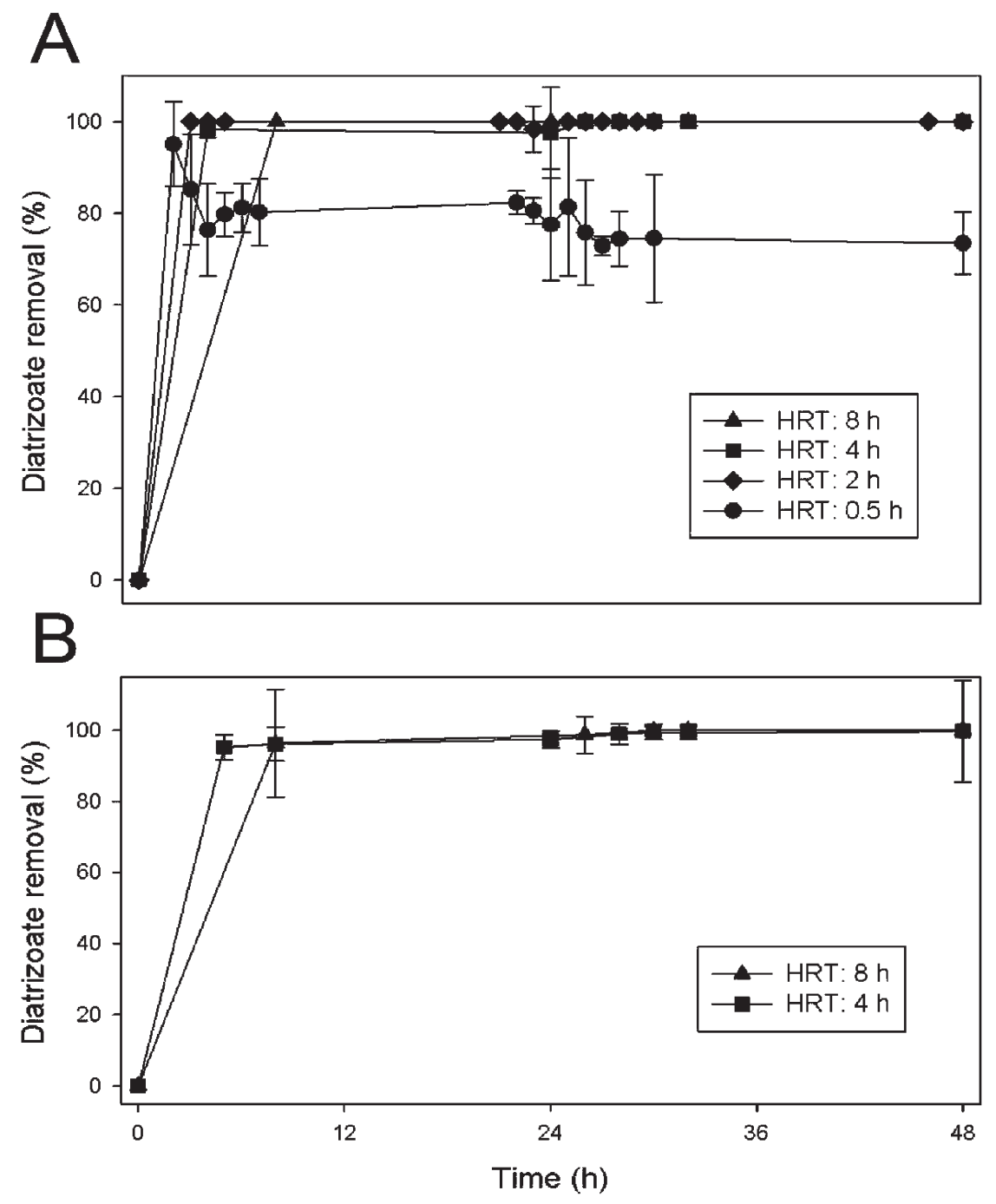

Figure 3. Continuous MEC experiments for the treatment of (A) synthetic medium at an applied voltage of $-0.8 \mathrm{~V}$. Different hydraulic retention times (HRT) in the cathodic compartment were used: $0.5 \mathrm{~h}, 2 \mathrm{~h}, 4 \mathrm{~h}$, and $8 \mathrm{~h}$. (B) Continuous treatment of hospital WWTP effluent at an applied voltage of $-0.8 \mathrm{~V}$. The provided HRT in the cathodic compartment were 4 and $8 \mathrm{~h}$. Error bars represent the standard deviation of triplicate measurements (sometimes smaller than symbols).

estimate to which extent each mechanism contributes to the complete removal of diatrizoate. Future research is needed to shed light on the importance of the catalytic properties of bio-Pd, and emerging techniques such as Tafel plots might increase our understanding on how bio-Pd catalysts affect the overpotential at the cathode. ${ }^{28}$ Yet, it was shown that the Coulombic efficiency of the electrochemical reduction of iopromide was very low $(<1 \%)$, and that hydrogen production at the cathode was the dominant reaction. ${ }^{24} \mathrm{By}$ introducing bio-Pd, one can also benefit from this sustainable $\mathrm{H}_{2}$ formation, through reductive catalysis.

The Use of Bio-Pd for the Reductive Catalysis of Diatrizoate. Pd catalysts are able to convert $\mathrm{H}_{2}$ to adsorbed atomic hydrogen, which is a powerful reducing agent. ${ }^{29}$ Therefore, Pd catalysts have been used before in the reductive treatment of ICM,${ }^{10,11}$ but pure hydrogen gas was externally supplied in these studies, which seems less practical and unsafe for continuous applications at large-scale. To overcome these challenges, we used the MEC to produce $\mathrm{H}_{2}$ at the cathode and to provide it gently to bio-Pd. This strategy was recently applied for TCE dechlorination in batch experiments, where introduction of $5 \mathrm{mg}$
bio-Pd $\mathrm{g}^{-1}$ graphite also enhanced the dechlorination rate by combining catalytic reduction with electrochemically formed $\mathrm{H}_{2}{ }^{22}$ In the present work, application of higher cell voltages resulted in higher diatrizoate removal rates, which is probably not only related to the direct electrochemical reduction but also to the elevated production of $\mathrm{H}_{2}$ and thus faster supply of new reactant to the catalyst. In other MEC configurations, higher $\mathrm{H}_{2}$ production rates and higher current densities were also observed when increasing the applied cell voltage. ${ }^{30}$ The rate of other catalytic reductions using Pd catalysts was also increased at higher $\mathrm{H}_{2}$ levels, for example, the reduction of nitric oxide. ${ }^{31}$

Complete Hydrodeiodination of Diatriozate Catalyzed by Bio-Pd. When applying a cell voltage of $-0.4 \mathrm{~V}$, the mass balance with the fully dehalogenated transformation product $\mathrm{DAB}$ could be closed after $24 \mathrm{~h}$ of recirculation. In their experiments with diatrizoate, Knitt et al. were able to close the carbon mass balance with $\mathrm{DAB}$ as well. ${ }^{10}$ They could confirm the sequential hydrodeiodination reaction of the core 2,4,6-triiodinated ring structure by LC-MS (with Dia- $\mathrm{HI}_{2}$ and Dia- $\mathrm{H}_{2} \mathrm{I}$ as intermediates). Sorption of diatrizoate to the graphite granules was negligible, which 


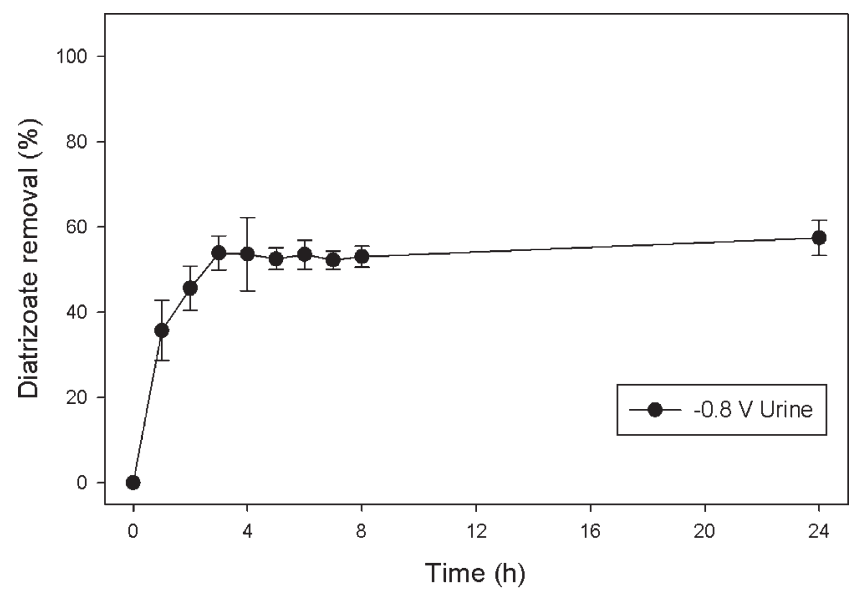

Figure 4. Batch recirculation experiments for the treatment of spiked urine. Percentage of diatrizoate removal as a function of time using the MEC at an applied voltage of $-0.8 \mathrm{~V}$. Error bars represent the standard deviation of triplicate measurements (sometimes smaller than symbols).

is consistent with previous reports in which no sorption of diatrizoate to sewage sludge, Pd catalysts or bio-Pd coated graphite was observed. ${ }^{10,22,32}$ Consequently, the low removal in open circuit was not related to sorption, but it is possible that decharging of the cathode electrodes and the concurrent loss of accumulated electrons caused further reduction of diatrizoate and/or production of some hydrogen gas in the first hours of the experiment. This would explain the sudden increase of the cathode potential at the start-up. However, the reduction of diatrizoate was not complete since no $\mathrm{DAB}$ formation was detected. The fact that charge can-to some extent-still be drawn from the cathode in open circuit was also reported for denitrification. ${ }^{33}$

It is very interesting to note that in the batch recirculation experiment at $-0.8 \mathrm{~V}$, further reduction of $\mathrm{DAB}$ was noticed. After the mass balance was initially closed after $2 \mathrm{~h}$ of recirculation, a gradual decrease of the DAB peak was observed during chromatographic analyses. It is difficult to propose a possible reduction pathway but reductive amide cleavage (see Chapter S5 and Figure SI3 in the SI) might be a plausible route. Indeed, in the case of electrochemical reduction of iomeprol, Zwiener et al. also observed that a transformation product was formed from the completely dehalogenated product by further cleavage of an amide bond. ${ }^{23}$ It is our hypothesis that the further reduction of $\mathrm{DAB}$ is also the reason why the recovered concentration of $\mathrm{DAB}$ decreased with increasing HRT during the continuous experiments in synthetic medium. Although Dia- $\mathrm{HI}_{2}$ and Dia- $\mathrm{H}_{2} \mathrm{I}$ were not detected at a HRT of 4 and $8 \mathrm{~h}$, the mass balance with DAB could not be closed, which might be related to further reduction. On the contrary, a HRT of 0.5 or $2 \mathrm{~h}$ seemed too short to ensure complete dehalogenation because the intermediates Dia- $\mathrm{HI}_{2}$ and Dia- $\mathrm{H}_{2} \mathrm{I}$ were still detected. Other studies indicated that the reaction rates for each deiodination step decreased with increasing rates of deiodination of ICM, probably because an increased requirement of the steric orientation. ${ }^{23}$ Also for bio-Pd catalysis, dehalogenation of Dia- $\mathrm{H}_{2}$ I seemed to be the most difficult step. ${ }^{11}$ Further research at elevated concentration is needed to elucidate the degradation pathway during reductive catalysis (see also SI Chapter S5).

Continuous Diatrizoate Removal from Hospital WWTP Effluent. Compared to the experiments in synthetic medium, the removal from hospital WWTP effluent was lower after $24 \mathrm{~h}$ of recirculation in batch, and only a HRT of $8 \mathrm{~h}$ was sufficient to ensure complete diatrizoate removal in the continuous test runs. The mass balance with $\mathrm{DAB}$ could not be closed but it could not be elucidated whether this was due to further reduction of the metabolite or incomplete dehalogenation, since it was not possible to quantify Dia- $\mathrm{HI}_{2}$ and $\mathrm{Dia}-\mathrm{H}_{2} \mathrm{I}$ in the effluent matrix. The lower removal rates are probably related to the lower diatrizoate concentration, the constituents of the environmental matrix and the presence of nontarget compounds. Although other studies reported on the inhibitory effect of natural organic matter (NOM) on reductive catalysis, ${ }^{10}$ bio-Pd catalyzed reduction of diatrizoate was not influenced by the presence of NOM. ${ }^{11}$ It is our hypothesis that the high iodine levels in the hospital WWTP effluent $\left(2.7 \mathrm{mg} \mathrm{L}^{-1}\right)$ influenced the performance of the catalyst. Knitt et al. have previously demonstrated that the inhibitory effects of iodide increase with increasing concentrations and suggested a competition mechanism between diatrizoate and iodide for the available catalytic sites. ${ }^{10}$ On the one hand, this means that the presence of other iodinated micropollutants in the wastewater influenced the reduction of diatrizoate, as it has been shown that iodohydrocarbons show a high affinity to the Pd surface. ${ }^{29}$ On the other hand, the functional group selectivity for iodine substituents is high and deiodination by $\mathrm{Pd}$ seems more favorable than dechlorination or debromination, which might render reductive catalysis suitable for targeted treatment of all ICM in water. ${ }^{29}$ Therefore, we suggest to look at the behavior of a mixture of ICM in further research.

Separate Treatment of ICM. The bio-Pd based MEC system opens a new window of opportunities for separate treatment of ICM point-sources by reductive catalysis, especially because of the unsatisfactory removal by other proposed end-of-pipe measures (e.g., ozonation or activated carbon). ${ }^{8,34}$ Not only posttreatment of effluents but also separate urine treatment is under consideration, $^{35}$ since $80 \%$ of ICM is excreted within 24 h. $^{36}$ Separate urine collection could decrease the pharmaceutical load by $60-70 \% .^{37}$ This study showed that urine treatment by the MEC system is feasible, but further development is needed because the removal efficiency was lower than in synthetic medium or WWTP effluent. The reduction was possibly affected by the presence of reducible compounds such as nitrate. ${ }^{38}$ Also sulfate can influence the catalyst performance, since reductive formation of sulfide is known to cause poisoning of the $\mathrm{Pd}$ catalyst. $^{39,40}$ To evaluate the lifetime of the catalyst in such conditions, longer continuous MEC runs should be carried out.

We were able to demonstrate that the loss of iodine from diatrizoate rendered the final product $\mathrm{DAB}$ readily biodegradable. While diatrizoate is not degradable by nitrifying biomass, reductive catalysis by the MEC leads to a single product, which is subjected to straightforward biodegradation (SI Chapter S9). In order to implement MEC systems at full-scale, it is of vital importance to minimize the power input needed to provide sufficient $\mathrm{H}_{2}$ for a complete dehalogenation of ICM at a short HRT. Together with the use of low cost graphite electrodes, this should allow treatment at an operational cost of a few euro cents per cubic meter. Provided optimal batch conditions, $4 \mathrm{mg}$ of diatrizoate was completely deiodinated in $2 \mathrm{~h}$, at a cell voltage of $-0.83 \mathrm{~V}$. A current of $552 \mathrm{~A} \mathrm{~m}^{-3} \mathrm{NCC}$ was produced (Table 2), meaning that an energy of $9.6 \mathrm{kWh} \mathrm{mol}^{-1}$ diatrizoate $\left(15.6 \mathrm{Wh} \mathrm{g}^{-1}\right)$ or $3.2 \mathrm{kWh} \mathrm{mol}^{-1} \mathrm{I}\left(25.2 \mathrm{Wh} \mathrm{g}^{-1} \mathrm{I}\right)$ was required. This is lower than the $41 \mathrm{kWh} \mathrm{mol}^{-1}$ iopromide or $13.7 \mathrm{kWh} \mathrm{mol}^{-1} \mathrm{I}$, which was previously reported by $\mathrm{Mu}$ et al. for a MEC operated at a 
similar cathode potential of $-0.8 \mathrm{~V}$ vs $\mathrm{SHE}$, but without bioPd. ${ }^{24}$ Assuming that all iodine measured in the hospital WWTP effluent $\left(2.7 \mathrm{mg} \mathrm{L}^{-1}\right)$ is associated with ICM, $68 \mathrm{Wh} \mathrm{m}^{-3}$ would be needed to remove all ICM under optimal conditions, which represents an electrical cost of $€ 0.005 \mathrm{~m}^{-3}$ (at $€ 0.08 \mathrm{kWh}^{-1}$ ). However, the continuous experiment with hospital WWTP effluent showed that an HRT of $8 \mathrm{~h}$ is needed to ensure complete dehalogenation in this matrix. At a voltage of $-0.81 \mathrm{~V}$ and a current of $588 \mathrm{~A} \mathrm{~m}^{-3} \mathrm{NCC}$, this results in an energy consumption of $7.6 \mathrm{kWh} \mathrm{m}^{-3}$ or $€ 0.61 \mathrm{~m}^{-3}$. To bridge this gap between optimal and environmental conditions, further studies are needed to decrease the power consumption and examine the long-term performance of the MEC. There are several ways to optimize the reactor performance, as discussed in SI Chapter S8.

\section{ASSOCIATED CONTENT}

S Supporting Information. More details on the MEC setup, the bio-Ag coated graphite and the hospital WWTP effluent can be found in the SI. Also the $\mathrm{H}_{2}$ measurements as well as the Pd concentrations found in the medium are reported. Furthermore, the results of the bio-Pd activity test and the biodegradability assessment of diatrizoate and $\mathrm{DAB}$ are presented. This material is available free of charge via the Internet at http://pubs.acs.org.

\section{AUTHOR INFORMATION}

\section{Corresponding Author}

*Phone: +32 926459 76; fax: +32 926462 48; e-mail address: Nico.Boon@UGent.be; Webpage: http://www.LabMET.UGent.be.

\section{ACKNOWLEDGMENT}

This work was supported by a $\mathrm{PhD}$ grant (B.D.G.) from the Research Foundation of Flanders (FWO). T.H. is supported by a project grant (No. 7741-02) from the FWO and by the Ghent University Multidisciplinary Research Partnership (MRP) "Biotechnology for a Sustainable Economy” (01 MRA 510W). L.V. is a postdoctoral fellows with the FWO. J.D. is supported by the Institute for the Promotion and Innovation through Science and Technology in Flanders (IWT, SB-091144). K.W. is funded by the Belgian Federal Science Policy Office (BELSPO) through the INRAM project (http://www.vliz.be/projects/inram). This work was supported by the EU Biotreat project (Contract No. 266039, call FP7-KBBE-2010.3.5.01). We gratefully thank Dirk Stockx and Mieke Naessens for their technical assistance during the chromatographic analyses, Peter Mast for his assistance in the SEM analyses, and Tim Lacoere for the help with Figure SI1. We acknowledge Jan Arends and Simon De Corte for critically reviewing this manuscript.

\section{REFERENCES}

(1) Perez, S.; Barcelo, D. Fate and occurrence of X-ray contrast media in the environment. Anal. Bioanal. Chem. 2007, 387 (4), 12351246.

(2) Weissbrodt, D.; Kovalova, L.; Ort, C.; Pazhepurackel, V.; Moser, R.; Hollender, J.; Siegrist, H.; McArdell, C. S. Mass flows of X-ray contrast media and cytostatics in hospital wastewater. Environ. Sci. Technol. 2009, 43 (13), 4810-4817.

(3) Ternes, T. A.; Hirsch, R. Occurrence and behavior of X-ray contrast media in sewage facilities and the aquatic environment. Environ. Sci. Technol. 2000, 34 (13), 2741-2748.
(4) Seitz, W.; Weber, W. H.; Jiang, J. Q.; Lloyd, B. J.; Maier, M.; Maier, D.; Schulz, W. Monitoring of iodinated X-ray contrast media in surface water. Chemosphere 2006, 64 (8), 1318-1324.

(5) Putschew, A.; Wischnack, S.; Jekel, M. Occurrence of triiodinated X-ray contrast agents in the aquatic environment. Sci. Total Environ. 2000, 255 (1-3), 129-134.

(6) Jones, O. A. H.; Voulvoulis, N.; Lester, J. N. Human pharmaceuticals in the aquatic environment-A review. Environ. Technol. 2001, 22 (12), 1383-1394.

(7) Daughton, C. G.; Ternes, T. A. Pharmaceuticals and personal care products in the environment: Agents of subtle change? Environ. Health Perspect. 1999, 107, 907-938.

(8) Ternes, T. A.; Stuber, J.; Herrmann, N.; McDowell, D.; Ried, A.; Kampmann, M.; Teiser, B. Ozonation: a tool for removal of pharmaceuticals, contrast media and musk fragrances from wastewater? Water Res. 2003, 37 (8), 1976-1982.

(9) Seitz, W.; Jiang, J. Q.; Schulz, W.; Weber, W. H.; Maier, D.; Maier, M. Formation of oxidation by-products of the iodinated X-ray contrast medium iomeprol during ozonation. Chemosphere 2008, 70 (7), $1238-1246$.

(10) Knitt, L. E.; Shapley, J. R.; Strathmann, T. J. Rapid metalcatalyzed hydrodehalogenation of iodinated X-ray contrast media. Environ. Sci. Technol. 2008, 42 (2), 577-583.

(11) Hennebel, T.; De Corte, S.; Vanhaecke, L.; Vanherck, K.; Forrez, I.; De Gusseme, B.; Verhagen, P.; Verbeken, K.; Van der Bruggen, B.; Vankelecom, I.; Boon, N.; Verstraete, W. Removal of diatrizoate with catalytically active membranes incorporating microbially produced palladium nanoparticles. Water Res. 2010, 44 (5), 1498-1506.

(12) De Windt, W.; Aelterman, P.; Verstraete, W. Bioreductive deposition of palladium (0) nanoparticles on Shewanella oneidensis with catalytic activity towards reductive dechlorination of polychlorinated biphenyls. Environ. Microbiol. 2005, 7 (3), 314-325.

(13) Hennebel, T.; De Gusseme, B.; Boon, N.; Verstraete, W. Biogenic metals in advanced water treatment. Trends Biotechnol. 2009, 27 (2), 90-98.

(14) Forrez, I.; Carballa, M.; Fink, G.; Wick, A.; Hennebel, T.; Vanhaecke, L.; Ternes, T.; Boon, N.; Verstraete, W. Biogenic metals for the oxidative and reductive removal of pharmaceuticals, biocides and iodinated contrast media in a polishing membrane bioreactor. Water Res. 2011, 45 (4), 1763-1773.

(15) Hennebel, T.; Simoen, H.; De Windt, W.; Verloo, M.; Boon, N.; Verstraete, W. Biocatalytic dechlorination of trichloroethylene with bio-palladium in a pilot-scale membrane reactor. Biotechnol. Bioeng. 2009, 102 (4), 995-1002.

(16) Logan, B. E. Exoelectrogenic bacteria that power microbial fuel cells. Nat. Rev. Microbiol. 2009, 7 (5), 375-381.

(17) Rabaey, K.; Verstraete, W. Microbial fuel cells: Novel biotechnology for energy generation. Trends Biotechnol. 2005, 23 (6), 291-298.

(18) Rozendal, R. A.; Hamelers, H. V. M.; Euverink, G. J. W.; Metz, S. J.; Buisman, C. J. N. Principle and perspectives of hydrogen production through biocatalyzed electrolysis. Int. J. Hydrogen Energy 2006, 31 (12), 1632-1640.

(19) Zeng, K.; Zhang, D. K. Recent progress in alkaline water electrolysis for hydrogen production and applications. Prog. Energy Combust. Sci. 2010, 36 (3), 307-326.

(20) Heinzmann, B.; Schwarz, R. J.; Schuster, P.; Pineau, C. Decentralized collection of iodinated $\mathrm{x}$-ray contrast media in hospitals-results of the feasibility study and the practice test phase. Water Sci. Technol. 2008, 57 (2), 209-215.

(21) Rabaey, K.; Ossieur, W.; Verhaege, M.; Verstraete, W. Continuous microbial fuel cells convert carbohydrates to electricity. Water Sci. Technol. 2005, 52 (1-2), 515-523.

(22) Hennebel, T.; Benner, J.; Clauwaert, P.; Vanhaecke, L.; Aelterman, P.; Callebaut, R.; Boon, N.; Verstraete, W. Dehalogenation of environmental pollutants in microbial electrolysis cells with biogenic palladium nanoparticles. Biotechnol. Lett. 2011, 33 (1), 89-95.

(23) Zwiener, C.; Glauner, T.; Sturm, J.; Worner, M.; Frimmel, F. H. Electrochemical reduction of the iodinated contrast medium iomeprol: 
iodine mass balance and identification of transformation products. Anal. Bioanal. Chem. 2009, 395 (6), 1885-1892.

(24) Mu, Y.; Radjenovic, J.; Shen, J.; Rozendal, R. A.; Rabaey, K.; Keller, J. Dehalogenation of iodinated X-ray contrast media in a bioelectrochemical system. Environ. Sci. Technol. 2011, 45 (2), 782-788.

(25) Huang, Y.-X.; Liu, X.-W.; Sun, X.-F.; Sheng, G.-P.; Zhang, Y.-Y.; Yan, G.-M.; Wang, S.-G.; Xu, A.-W.; Yu, H.-Q. A new cathodic electrode deposit with palladium nanoparticles for cost-effective hydrogen production in a microbial electrolysis cell. Int. J. Hydrogen Energy 2011, 36 (4), 2773-2776.

(26) Logan, B. E.; Hamelers, B.; Rozendal, R. A.; Schrorder, U.; Keller, J.; Freguia, S.; Aelterman, P.; Verstraete, W.; Rabaey, K. Microbial fuel cells: Methodology and technology. Environ. Sci. Technol. 2006, 40 (17), 5181-5192.

(27) Rasten, E.; Hagen, G.; Tunold, R. Electrocatalysis in water electrolysis with solid polymer electrolyte. Electrochim. Acta 2003, 48 (25-26), 3945-3952.

(28) Selembo, P. A.; Merrill, M. D.; Logan, B. E. The use of stainless steel and nickel alloys as low-cost cathodes in microbial electrolysis cells. J. Power Sources 2009, 190 (2), 271-278.

(29) Mackenzie, K.; Frenzel, H.; Kopinke, F. D. Hydrodehalogenation of halogenated hydrocarbons in water with Pd catalysts: Reaction rates and surface competition. Appl. Catal., B 2006, 63 (3-4), 161-167.

(30) Cheng, S.; Logan, B. E. High hydrogen production rate of microbial electrolysis cell (MEC) with reduced electrode spacing. Bioresour. Technol. 2011, 102 (3), 3571-3574.

(31) Qi, G. S.; Yang, R. T.; Rinaldi, F. C. Selective catalytic reduction of nitric oxide with hydrogen over Pd-based catalysts. J. Catal. 2006, 237 (2), 381-392.

(32) Haiss, A.; Kummerer, K. Biodegradability of the X-ray contrast compound diatrizoic acid, identification of aerobic degradation products and effects against sewage sludge micro-organisms. Chemosphere 2006, 62 (2), 294-302.

(33) Virdis, B.; Read, S. T.; Rabaey, K.; Rozendal, R. A.; Yuan, Z.; Keller, J. r. Biofilm stratification during simultaneous nitrification and denitrification (SND) at a biocathode. Bioresour. Technol. 2011, 102 (1), 334-341.

(34) Seitz, W.; Jiang, J. Q.; Weber, W. H.; Lloyd, B. J.; Maier, M.; Maier, D. Removal of iodinated X-ray contrast media during drinking water treatment. Environ. Chem. 2006, 3 (1), 35-39.

(35) Larsen, T. A.; Alder, A. C.; Eggen, R. I. L.; Maurer, M.; Lienert, J. Source separation: will we see a paradigm shift in wastewater handling? Environ. Sci. Technol. 2009, 43 (16), 6121-6125.

(36) Mützel, W.; Langer, M.; Keysser, R. Renal excretion of iopromide and iopamidol after intravenous administration in digital substraction angiography. Fortschritte auf dem Gebiete der Rontgenstrahlen und Nuklearmedezin. Ergänzungsband 1989, 128, 101-104.

(37) Lienert, J.; Burki, T.; Escher, B. I. Reducing micropollutants with source control: Substance flow analysis of 212 pharmaceuticals in faeces and urine. Water Sci. Technol. 2007, 56 (5), 87-96.

(38) Shuai, D.; Chaplin, B. P.; Shapley, J. R.; Menendez, N. P.; McCalman, D. C.; Schneider, W. F.; Werth, C. J. Enhancement of oxyanion and diatrizoate reduction kinetics using selected azo dyes on Pd-based catalysts. Environ. Sci. Technol. 2010, 44 (5), 1773-1779.

(39) Angeles-Wedler, D.; MacKenzie, K.; Kopinke, F. D. Permanganate oxidation of sulfur compounds to prevent poisoning of $\mathrm{Pd}$ catalysts in water treatment processes. Environ. Sci. Technol. 2008, 42 (15), 5734-5739.

(40) Alfonso, D. R.; Cugini, A. V.; Sholl, D. S. Density functional theory studies of sulfur binding on $\mathrm{Pd}, \mathrm{Cu}$ and $\mathrm{Ag}$ and their alloys. Surf. Sci. 2003, 546 (1), 12-26.

\section{NOTE ADDED AFTER ASAP PUBLICATION}

The authors' first and last names were reversed in the version published ASAP on June 10, 2011. The corrected version was published on June 29, 2011. 